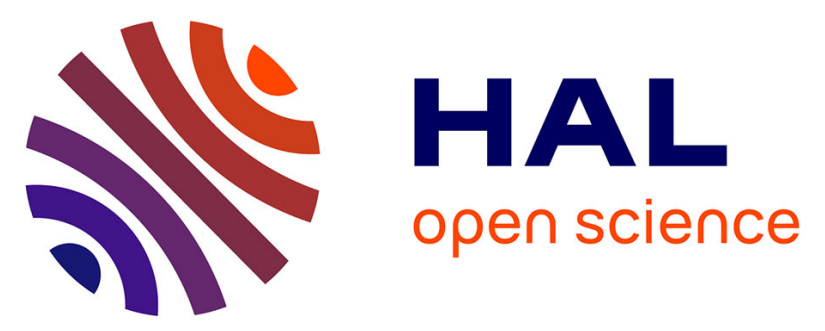

\title{
Annealing effect on the electrical proprieties of IF(CN2)2-meta based OTFTs: Thermal behavior and modeling of charge transport
}

Nawel Arfaoui, M. Mahdouani, I. Bouhadda, Cyril Poriel, R. Bourguiga, Emmanuel Jacques, M. Chevrier, S. Bebiche

\section{To cite this version:}

Nawel Arfaoui, M. Mahdouani, I. Bouhadda, Cyril Poriel, R. Bourguiga, et al.. Annealing effect on the electrical proprieties of IF(CN2)2-meta based OTFTs: Thermal behavior and modeling of charge transport. Superlattices and Microstructures, 2018, 123, pp.286 - 296. 10.1016/j.spmi.2018.09.011. hal-01928239

HAL Id: hal-01928239

https://hal-univ-rennes1.archives-ouvertes.fr/hal-01928239

Submitted on 14 Dec 2018

HAL is a multi-disciplinary open access archive for the deposit and dissemination of scientific research documents, whether they are published or not. The documents may come from teaching and research institutions in France or abroad, or from public or private research centers.
L'archive ouverte pluridisciplinaire HAL, est destinée au dépôt et à la diffusion de documents scientifiques de niveau recherche, publiés ou non, émanant des établissements d'enseignement et de recherche français ou étrangers, des laboratoires publics ou privés. 


\section{Annealing effect on the electrical proprieties of $\operatorname{IF}\left(\mathrm{CN}_{2}\right)_{2}$-meta based OTFTs: thermal behavior and modeling of charge transport}

\section{N. Arfaoui ${ }^{a}$, M. Mahdouania ${ }^{a}$ I. Bouhadda ${ }^{b}$, C. Poriel $^{c}$, R. Bourguiga ${ }^{a}$, E. Jacques ${ }^{\mathrm{d}}$, M. Chevrier, S. Bebiche ${ }^{d}$}

${ }^{a}$ Laboratoire de Physique des Matériaux: Structure et Propriétés, Groupe Physique des Composants et Dispositifs Nanométriques, Faculté des Sciences de Bizerte, 7021 Jarzouna-Bizerte, Université de Carthage, Tunisia.

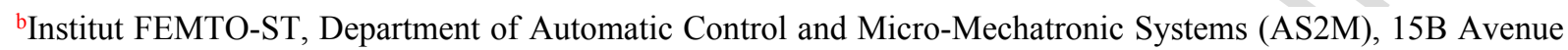
des Montboucons, 25030, Besançon, France.

'UMR CNRS 6226, Institut des Sciences Chimiques de Rennes, Équipe Matière Condensée et Systèmes Électroactifs, Bat 10C, Campus de Beaulieu, 35042 Rennes Cedex, France.

dUMR CNRS 6164-Institut d'Électronique et des Télécommunications de Rennes-Département Microélectronique \& Microcapteurs, Bât.11B, Université Rennes 1, Campus de Beaulieu 35042 Rennes Cedex, France.
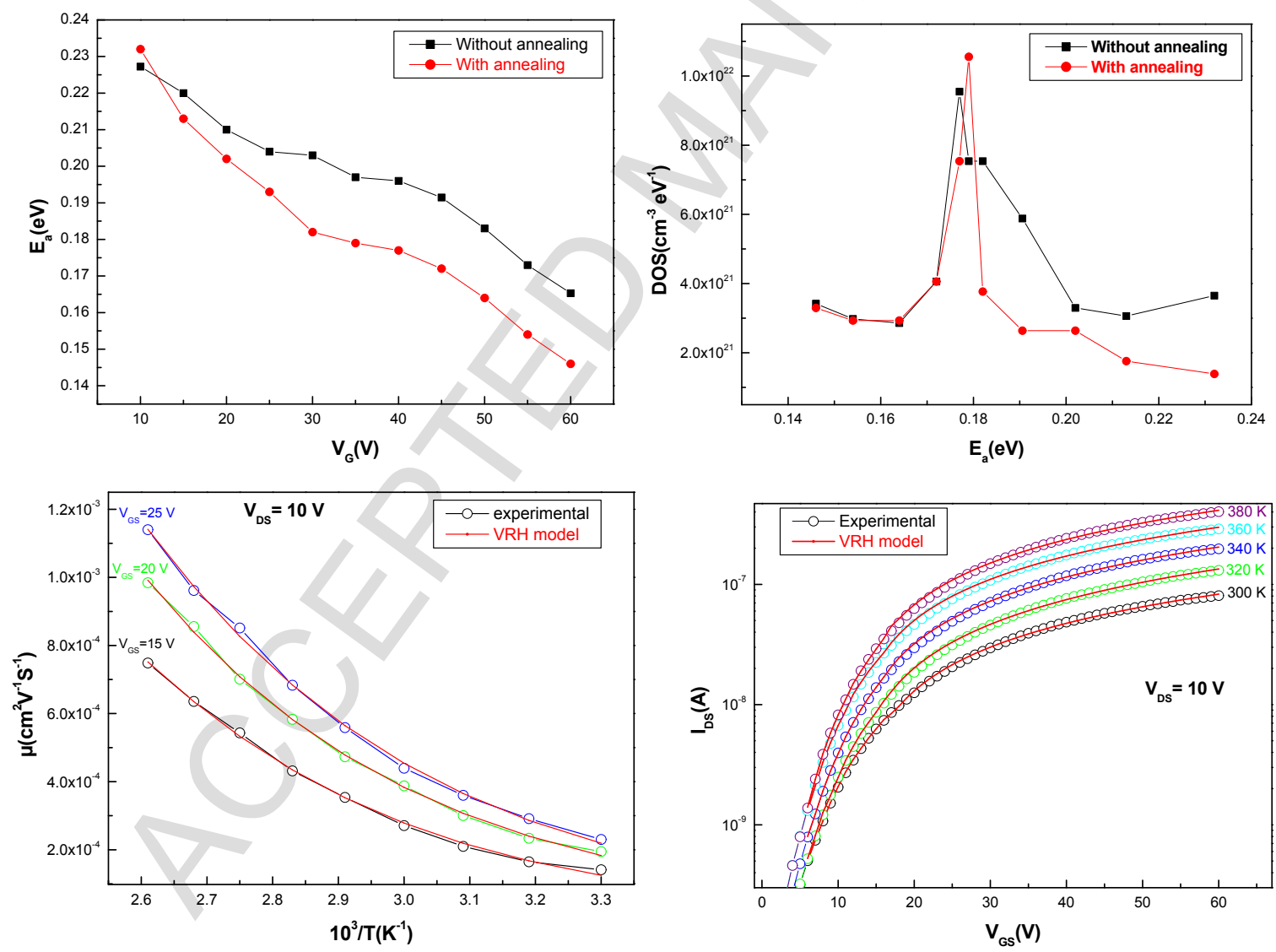
Annealing effect on the electrical proprieties of $\operatorname{IF}\left(\mathrm{CN}_{2}\right)_{2}$-meta based OTFTs: thermal behavior and modeling of charge transport

\section{N. Arfaoui ${ }^{a *}$, M. Mahdouani ${ }^{a}$, I. Bouhadda ${ }^{b}$, C. Poriel $^{c}$, R. Bourguiga ${ }^{a}$, E. Jacques ${ }^{d}$, M.}

\section{Chevrierc $^{c}$, S. Bebiche ${ }^{\mathrm{d}}$}

${ }^{a}$ Laboratoire de Physique des Matériaux: Structure et Propriétés, Groupe Physique des Composants et Dispositifs Nanométriques, Faculté des Sciences de Bizerte, 7021 Jarzouna-Bizerte, Université de Carthage, Tunisia.

bInstitut FEMTO-ST, Department of Automatic Control and Micro-Mechatronic Systems (AS2M), 15B Avenue des Montboucons, 25030, Besançon, France.

'UMR CNRS 6226, Institut des Sciences Chimiques de Rennes, Équipe Matière Condensée et Systèmes Électroactifs, Bat 10C, Campus de Beaulieu, 35042 Rennes Cedex, France.

dUMR CNRS 6164-Institut d'Électronique et des Télécommunications de Rennes-Département Microélectronique \& Microcapteurs, Bât.11B, Université Rennes 1, Campus de Beaulieu 35042 Rennes Cedex, France.

\section{Abstract}

N-type organic thin film transistors (OTFT) based on $\operatorname{IF}\left(\mathrm{CN}_{2}\right)_{2}$-meta were fabricated in bottom gate-bottom contact configuration at substrate temperature of $80{ }^{\circ} \mathrm{C}$ and deposition rate $d_{r}$ of $0,4 \AA / s$, using the epoxy based photoresist SU-8 as gate insulator. A thermal annealing of fabricated devices under nitrogen for $90 \mathrm{~min}$ at $150{ }^{\circ} \mathrm{C}$ has enhanced their performances. In order to understand the annealing effect on the performance of $\operatorname{IF}\left(\mathrm{CN}_{2}\right)_{2}{ }^{-}$ meta based OFETs, we have analyzed their thermal behavior by characterizing them electrically over a temperature range from 300 up to $380 \mathrm{~K}$ while $10 \mathrm{~K}$ step was used. Accordingly, we have estimated and compared the activation energy of the mobility $E_{a}$ and the density of state DOS before and after annealing treatment. The present study has shown that the improvement of OFETs performances is due to the increased crystallinity of $\operatorname{IF}\left(\mathrm{CN}_{2}\right)_{2}$-meta layer thereby to the enhanced $\mathrm{SU}-8 / \mathrm{IF}\left(\mathrm{CN}_{2}\right)_{2}$-meta and $\mathrm{Au} / \mathrm{IF}\left(\mathrm{CN}_{2}\right)_{2}$-meta interfaces. Finally, to understand the charge transport mechanism dominating in the $\operatorname{IF}\left(\mathrm{CN}_{2}\right)_{2}{ }^{-}$ meta molecule and to model the fabricated OFETs, we have successfully reproduced the dependence of mobility with temperature and the transfer and output characteristics using an analytical model based on variable range hopping (VRH) theory.

Keywords: $\mathrm{N}$ type-OTFTs, annealing effect, temperature dependence, density of states, modeling the charge transport.

\footnotetext{
* Corresponding author: nawelarfaoui20@yahoo.fr
} 


\section{Introduction}

During the past decades, organic electronics have taken important dimension in the world of advanced technology due to their advantage of low cost, room-temperature operating condition, as well as their potential applications including organic light-emitting diodes (OLED) [1], organic solar cells [2], and organic field-effect transistor (OFET) [3-4]. Particularly, OFETs have received much attention due to possible incorporation in integrated organic circuits [5], which is a serious challenge for the future of organic electronic. Consequently in the past years many research efforts have focused on developing new molecules as active layers in order to satisfy OFETs qualification requirements in terms of electrical performance and ambient stability [6-7]. It has already been reported that P- type OFETs exhibit field effect mobility as high as $0.1-8 \mathrm{~cm}^{2} \mathrm{~V}^{-1} \mathrm{~s}^{-1}[8-9]$, such devices are commonly based on p-type molecules such as oligothiophene [10], pyrene and its derivatives [11] and pentacene [12]. However N-type OFETs, based on n-type molecules exist with a limited number compared to p-type molecules [13], materials such as $\mathrm{N}$-alkyl perylene tetracarboxylic diimides (PTCDI-R) [14] and fullerene $\left(\mathrm{C}_{60}\right)[15]$ are the most used ones. Although, the n-type OFETs still suffer from low carrier mobility as compared to p-type OFETs, most of them present field effect mobility lower than $1 \mathrm{~cm}^{2} \mathrm{~V}^{-1} \mathrm{~s}^{-1}$ [16]. Therefore, many studies are developed to understand the physico-chemical properties of these materials, in order to synthesize new n-type molecules with efficient electron mobilities comparative with the hole mobilities. In the last ten years, a new generation of semi-conductors, namely dihydroindenofluorenes has appeared in the literature possessing promising electronic proprieties [17]. Initially the dihydroindenofluorene backbone was used to construct materials for fluorescent OLEDs [18-19], phophorescent OLEDs [20-22] and even solar cells [23]. More recently, dihydroindenofluorene backbone has also been used to construct electron-poor materials for n-type OFETs [24-25]. In the present work, the focus is brought on (IF(CN2)2-meta) derivative, this molecule has shown relatively correct electron mobility and electrical stability when used as active layer in OFET devices [26]. In addition these promising proprieties have allowed to incorporate the $(\mathrm{IF}(\mathrm{CN} 2) 2)$ based n-channel OFETs in an integrated circuit [26]. Despite these promising results, the electron mobility of this new family of n-type organic semiconductor (OSC) remains low compared to that of p-type OSC. In fact, for the aim to enhance the performance of n-channel OFETs, several studies have been done [27-28] proving that the strong Л- Л stacking of molecular orbitals induced by the planar geometry of molecule, leads to an increase of mobility [29]. It was demonstrated also 
that the performances of these devices have improved by modifying the drain-source electrodes by self-assembled monolayers (SAMs) [16] and by improving the elaboration conditions of the active layer [26]. A thermal annealing treatment of devices is another approach to enhance the carrier mobility [30-31] because it is related to the reorganization of the organic molecules in thin films leading to higher crystallinity and lower the density of defects [32] which eases the charge transport in the active layer.

Adding to that, understanding the charge transport in the active layer is essential for modeling OTFTs devices [33]. In spite of the large amount of works [34-36] done to understand the transport charge in organic materials, so far, it is not well understood and it is still the principal aim of several researchers. Based on classical MOS (metal-oxidesemiconductor) transistor models, several models of OTFTs [37-40] have been developed with introducing empirical fitting parameters [37-39]. The most pertinent one is the variable range hopping (VRH) model proposed by Vissenberg and Matters [41]. This model assumes that the charge transport in OSC is thermally activated and it is governed by the hopping of carriers between localized states [41]. It has been successfully used to describe the field effect mobility in OTFTs [39].

In the present study, we report on the fabrication and characterization of $\operatorname{IF}\left(\mathrm{CN}_{2}\right)_{2}$-meta based n-channel OFETs using epoxy based photoresist SU-8 as gate insulator. The $\operatorname{IF}\left(\mathrm{CN}_{2}\right)_{2}$ meta appears as a promising n-type semiconductor with high electron mobility. The performances of fabricated devices were widely improved when thermal annealing was given at $150{ }^{\circ} \mathrm{C}$ for $90 \mathrm{~min}$. The cause of this improvement was investigated by characterizing devices at different temperature ranging from $300 \mathrm{~K}$ to $360 \mathrm{~K}$ in steps of $10 \mathrm{~K}$ and comparing the extracted activation energy $E_{a}$ and density of states DOS before and after annealing. Finally, to understand the transport charge phenomena in $\operatorname{IF}\left(\mathrm{CN}_{2}\right)_{2}$-meta based TFTs, we used the variable range hopping $(\mathrm{VRH})$ model to reproduce the dependence of field effect mobility $\mu_{\mathrm{FET}}$ with temperature and the U-V characteristics of these new n-type OFETs generation.

\section{Experimental details}

The IF $\left(\mathrm{CN}_{2}\right)_{2}$-meta based n-channel OTFTs were fabricated on previously cleaned glass substrate with bottom gate bottom contact configuration as shown in Fig. 1. The first step consists of photolithography on $150 \mathrm{~nm}$ evaporated aluminum layer as a gate contact. The gate dielectric is a $320 \mathrm{~nm}$ of spin coated SU-8 photoresist. To define the Source and drain contacts, $60 \mathrm{~nm}$ evaporated gold layer is used by a photolithography step. The final 
fabrication step is the thermal deposition of $8 \mathrm{~nm}$ of $\operatorname{IF}\left(\mathrm{CN}_{2}\right)_{2}$-meta molecule, with a base chamber pressure of $3.10^{-7}$ mbar, moderate deposition rate $d_{r}$ of $0.4-0.7 \mathrm{~A} / \mathrm{s}$ and substrate temperature $\mathrm{T}_{\text {sub }}$ of $80{ }^{\circ} \mathrm{C}$. All electrical characterizations of the fabricated devices were performed under nitrogen ambient using Keithley 2636A. The device temperature was varied from $300 \mathrm{~K}$ to $360 \mathrm{~K}$ by means of a MMR Technologies controller (model K-20). To study the annealing effect on the electronic proprieties of OFETs, the fabricated samples were annealed for $90 \mathrm{~min}$ under nitrogen at $150{ }^{\circ} \mathrm{C}$.

\section{Results and discussion}

\section{1 .}

\section{Morphological characterization of IF $\left(\mathrm{CN}_{2}\right)_{2}$-meta}

The indenofluorene derivative molecule $\left(\operatorname{IF}\left(\mathrm{CN}_{2}\right)_{2}\right.$-meta) is characterized by a planar geometry. As shown in Fig.2 (a), it is formed by three phenyl cycles connected by two bridges, on which dicyanovinylene groups were introduced in the meta configuration in order to lower the LUMO level, which is crucial for achieving efficient electron injection transport. The HOMO-LUMO gap of $\operatorname{IF}\left(\mathrm{CN}_{2}\right)_{2}$-meta is $2.1 \mathrm{eV}$ and its LUMO energy level, is measured at $-3.81 \mathrm{eV}$. The Atomic Force Microscopy (AFM) image of $\operatorname{IF}\left(\mathrm{CN}_{2}\right)_{2}$-meta film deposed at substrate temperature of $80{ }^{\circ} \mathrm{C}$ is represented in Fig.2 (b). Film morphology consists of compact small crystal grains well ordered and distributed homogeneously with a size of 60 $\mathrm{nm}[26]$.

3.2 .

Ele

\section{ctrical characterization of IF $\left(\mathrm{CN}_{2}\right)_{2}$-meta based TFT}

Devices were characterized under nitrogen ambient at fixed channel length (L) of $20 \mu \mathrm{m}$ and fixed channel width (W) of $1000 \mu \mathrm{m}$ and at room temperature. Output characteristic were measured by varying $\mathrm{V}_{\mathrm{DS}}$ from 0 to $70 \mathrm{~V}$ with $2 \mathrm{~V}$ step and varying $\mathrm{V}_{\mathrm{GS}}$ from 0 to $60 \mathrm{~V}$ with $10 \mathrm{~V}$ step as shown in Fig.3 (a). While, transfer characteristics were measured by varying the gate-source voltage $\mathrm{V}_{\mathrm{GS}}$ from $-20 \mathrm{~V}$ to $60 \mathrm{~V}$ with a $1 \mathrm{~V}$ step at constant drain-source voltage VDS of 10V in the linear regime as shown in Fig.3 (b).

As shown in Fig.3 (a-b), the drain current increases with positive gate and drain voltage, thus, the $\operatorname{IF}\left(\mathrm{CN}_{2}\right)_{2}$ meta based OFET exhibit the expected behavior for a n-channel field effect transistor. The drain-source current $\mathrm{I}_{\mathrm{DS}}$ in the linear regime $\left(\mathrm{V}_{\mathrm{DS}}<<\mathrm{V}_{\mathrm{GS}}-\mathrm{V}_{\mathrm{th}}\right)$ is calculated using the following expression

$$
I_{D S}=\frac{W}{L} \mu C_{i}\left(V_{G S}-V_{t h}\right) V_{D S}
$$


Where, $\mathrm{W}$ and $\mathrm{L}$ are the width and length of the channel, $\mu$ is the field effect mobility, $\mathrm{C}_{\mathrm{i}}$ is the gate insulator capacitance per area unit $\left(\mathrm{C}_{\mathrm{i}}=7.6 \mathrm{nF} / \mathrm{cm}^{2}\right)$.

The field effect mobility in the linear regime $\mu_{\text {lin }}$ calculated at $\mathrm{V}_{\mathrm{DS}}=10 \mathrm{~V}$ using Eq. (2) reached the value of $5 \times 10^{-4} \mathrm{~cm}^{2} \mathrm{~V}^{-1} \mathrm{~s}^{-1}$, the on/off ration was found to be $10^{5}$ and the threshold voltage $\mathrm{V}_{\text {th }}$ is equal to $14 \mathrm{~V}$.

$$
\mu_{\text {lin }}=\frac{L}{W C_{i} V_{D S}}\left[\frac{\delta I_{D S}}{\delta V_{G S}}\right]_{V_{D S}=c t e}
$$

At room temperature the $\operatorname{IF}\left(\mathrm{CN}_{2}\right)_{2}$ meta based OFET shows a promising performance compared to others n-type OFETs. In the next part, we report the thermal behavior and the influence of annealing treatment on the electronic proprieties of fabricated devices.

\section{3.}

The

\section{rmal behavior}

\subsubsection{Influence of annealing treatment on the IF $\left(\mathrm{CN}_{2}\right)_{2}$-meta based TFT performances}

The fabricated devices were annealed for 90 min under nitrogen at $150{ }^{\circ} \mathrm{C}$. Fig. 4 (a-b) present the output characterization compared before and after annealing treatment. Fig. 5 (a-b) shows the comparison between transfer characteristics and the linear mobility measured before and after annealing.

As shown in Fig.4 (a-b), and Fig.5 (a-b), the annealing treatment enhanced the performance of fabricated device. The linear mobility was increased from $5 \times 10^{-4} \mathrm{~cm}^{2} \mathrm{~V}^{-1} \mathrm{~s}^{-1}$ to $8.5 \times 10^{-4} \mathrm{~cm}^{2} \mathrm{~V}^{-}$ ${ }^{1} \mathrm{~S}^{-1}$, the on/off ration was increased from $10^{4}$ to $10^{5}$ and $\mathrm{V}_{\text {th }}$ was decreased from $14 \mathrm{~V}$ to $11 \mathrm{~V}$. The cause of this improvement was investigated in the next part by analyzing the thermal behavior of fabricated devices at different temperature and estimating the activation energy of the mobility $\mathrm{E}_{\mathrm{a}}$ and the density of states DOS.

\subsubsection{Temperature dependence}

We characterized the $\operatorname{IF}\left(\mathrm{CN}_{2}\right)_{2}$-meta based TFTs electrically, while the temperature was varied in the range of 300-380 K. The transfer characteristics of OFETs measured at $\mathrm{V}_{\mathrm{DS}}=10$ $\mathrm{V}$ before and after annealing were represented in Fig.6 (a-b).

The stretching of transfer curves observed after annealing treatment can be explained by the variation in the density of states (DOS) of the active layer.

From the transfer characteristics, the threshold voltage $V_{\text {th }}$ was extracted at $V_{D S}=10 \mathrm{~V}$ than it was compared before and after annealing as a function of temperature in Fig.7 (a).

The calculated threshold voltage of $\operatorname{IF}\left(\mathrm{CN}_{2}\right)_{2}$-meta based-TFTs before and after annealing decreases with the temperature which indicates that the charge transport is thermally 
activated. The shift of $\mathrm{V}_{\text {th }}$ seen after annealing could be due to the presence of trapped charge at the insulator/semiconductor interface [42-43]. The total trapped charge density $\mathrm{N}_{\text {tr }}$ including charges those trapped at the insulator/organic and the metal/organic interfaces, as well as those trapped in the localized states in the channel can be calculated using the following expression [44]:

$$
N_{t r}=\frac{C_{i}\left|V_{t h-} V_{t 0}\right|}{e}
$$

Where, $\mathrm{C}_{\mathrm{i}}$ is the insulator capacitance per unit area, $\mathrm{V}_{\mathrm{t} 0}$ is the turn-on voltage and $\mathrm{e}$ is the electronic charge.

The variation of $\mathrm{N}_{\mathrm{tr}}$ with the temperature calculated before and after annealing treatment was compared in Fig.7 (b).

Fig.7 (b) shows that the total trapped charge density was reduced after annealing treatment which can be due to the decrease of defects density at the active layer and at the SU-8/ $\operatorname{IF}\left(\mathrm{CN}_{2}\right)_{2}$-meta and the $\mathrm{Au} / \mathrm{IF}\left(\mathrm{CN}_{2}\right)_{2}$-meta interface.

Fig. 8 (a-b) plots the variation of field effect mobility versus gate voltage in the linear regime at various temperatures before and after annealing.

The carrier mobilities of $\operatorname{IF}\left(\mathrm{CN}_{2}\right)_{2}$-meta based TFTs has been plotted as a function of the reciprocal temperature (Arrhenius plot) for different gate voltages (Fig 9 (a-b)). Accordingly, we estimate the activation energy of the mobility before and after annealing treatment by fitting to the following equations:

$$
\mu=\mu_{0} e^{-\frac{E_{a}}{k_{B} T}}
$$

Where, $\mathrm{k}_{\mathrm{B}}$ is the Boltzmann constant and $\mathrm{E}_{\mathrm{a}}$ is the activation energy of the mobility.

Fig. 10 (a) shows the activation energy of the mobility as a function of gate voltage before and after annealing treatment.

As observed in Fig.10 (a), the annealing treatment of fabricated devices reduced the activation energy of the mobility, consequently, electrons can move easily from occupied trap states to the delocalized band edge which can explain the increase of carrier's mobility after annealing treatment. We note also that the decrease $\mathrm{E}_{\mathrm{a}}$ with the gate voltage after thermal annealing is faster than that before the annealing which correspondent to easily shift of the Fermi level toward the conduction band caused by the filling of empty traps by injected electron from 
contact. Thus the annealing treatment eases the injection of electron into the $\operatorname{IF}\left(\mathrm{CN}_{2}\right)_{2}$-meta layer. This result is due to the improved contact between insulator and semiconductor.

The fast decrease of $E_{a}$ with the gate voltage after annealing treatment indicates a lower density of states DOS in the gap which can be calculated from the following expression [45]:

$$
D O S=\frac{C_{i} 1}{e_{t}\left(d E_{\left.a / d V_{G S}\right)}\right.}
$$

Where, $E_{a}$ is the activation energy of the mobility, $C_{i}$ the capacitance of the insulator per unit area, $t$ is the channel thickness and e is the elementary charge. The variation of the density of states as a function of $\mathrm{E}_{\mathrm{a}}$ before and after annealing is compared in Fig. 10 (b).

The calculated DOS in the gap of $\operatorname{IF}\left(\mathrm{CN}_{2}\right)_{2}$-meta layer before and after thermal annealing shows an exponential distribution which indicates the presence of deep and band tail states. The band tail states are generally induced by structural disorder [46-47]. In Fig.10 (b), we observed a reduction in the width of the band tail after the annealing treatment which could be due to the reorganization of molecules and the improved crystallinity of $\operatorname{IF}\left(\mathrm{CN}_{2}\right)_{2}$-meta layer. Thus, the enhanced field effect mobility of $\operatorname{IF}\left(\mathrm{CN}_{2}\right)_{2}$-meta based TFT after annealing can be explained by the increased ordering of molecules which facilitate the hopping of electrons from one state to another.

The analyze of the thermal behavior of the fabricated devices proves that the enhanced performances after annealing treatment can be explained by the reduction of defect density at insulator/OSC and electrodes /OSC interfaces, and the reorganization of molecules in the $\operatorname{IF}\left(\mathrm{CN}_{2}\right)_{2}$-meta layer. It can be due also to the reduction of contact resistance effect after annealing treatment.

The last part of paper consists in modeling the charge transport of fabricated devices. According the temperature dependent field-effect mobility measurements, we noted that the charge transport is thermally activated which can be described by hopping process. The multiple releases trapping (MTR) model is suitable for higher mobility systems. Thus we have used the variable range hopping (VRH) model to describe the charge transport mechanism in fabricated OFETs.

\section{Analytic model:}

4.1. Mo

\section{deling the field effect mobility}

The variable range hopping model (VRH) developed by Vissenberg and Matters [41] to understand the transport mechanisms in disordered semiconductors and to modeling the 
electrical characteristics in OFETs [41], is based on thermally activated charge hopping through an exponential distribution of localized states [39]. According the VRH model, the expression of conductivity $\sigma$ can be obtained using the localized states distribution and the percolation theory [48-50] as following [51]:

$$
\sigma(\delta, T)=\sigma_{0}\left[n \frac{\delta\left(\frac{T_{0}}{T}\right)^{4} \sin \left(\pi_{\frac{T}{T_{0}}}\right)}{(2 \alpha)^{3} B_{c}}\right]^{\frac{T_{0}}{T}}
$$

Where, $\mathrm{n}$ is the number of localized states per unit volume (density), $\mathrm{T}$ is the absolute temperature, $T_{0}$ is the characteristic temperature of the localized states, $\sigma_{0}$ is the prefactor of the conductivity, $\mathrm{Bc} \approx 2.8$ is a critical number for the onset of percolation for three dimensional amorphous systems [50], $\delta$ is the charge carrier occupation and $\alpha$ is an effective overlap parameter between localized states.

The field effect mobility according to Vissenberg and Matters is a function of temperature and charge carriers' concentration can be expressed as following [41]:

$$
\mu_{F E T}=\frac{\sigma(\delta, T)}{e \delta N_{t}}
$$

Where, $\mathrm{e}$ is the elemental charge, $\mathrm{N}_{\mathrm{t}}$ is the number of states per unit volume Supposing that the transport current is parallel to the insulator-semiconductor interface [52], and using the VRH theory developed in $[41,51]$, we get the final expression of field effect mobility according Vissenberg and Matters:

$$
\mu_{V R H}=\frac{\sigma_{0}}{e}\left[\frac{\left(\frac{0}{T}\right)^{4} \sin \left(\pi \pi_{\frac{T}{T_{0}}}\right)}{(2 \alpha)^{3} B_{c}}\right]^{\frac{T_{0}}{T}}\left[\frac{\left(C_{i} V_{G S}\right)^{2}}{2 K_{B} T_{0} \varepsilon_{s}}\right]^{\frac{T_{0}}{T}-1}
$$

Where, $\mathrm{k}_{\mathrm{B}}$ is the Boltzmann's constant, $\varepsilon_{\mathrm{S}}$ is the relative dielectric constant of the organic semiconductor $C \mathrm{i}$ is the insulator capacitance per unit area.

We reproduced the temperature dependence mobility of fabricated TFTs for different gate voltage before and after thermal annealing using Eq. (8) and the obtained results of the modeling are shown respectively in Fig. 11 (a-b).

Fig.11 (a-b) shows a good agreement between calculated and experimental data, the obtained fit parameters before and after annealing are summarized in Table 1. 
Based in the variable rage hopping theory [53], the current-voltage characteristics of OFETs can be modeled using the following expression [33]:

$$
I_{D S}=\frac{W}{L} \int_{V_{S}}^{V_{D}} \int_{0}^{t} \sigma(\delta, T, V) d y d V_{c h}
$$

Where, $\mathrm{L}$ and $\mathrm{W}$ are the channel width and length, respectively, $\mathrm{V}_{\mathrm{s}}$ and $\mathrm{V}_{\mathrm{D}}$ are the source and drain voltages, respectively, $\mathrm{t}$ is the organic semiconductor thickness, $y$ is the direction perpendicular to the oxide semiconductor interface and $\mathrm{V}_{\mathrm{ch}}$ is the channel potential.

Developing Eq. (9) using the gradual channel approximation in the usual MOSFET (metaloxide-semiconductor field effect transistor) and the VRH theory [51], we get finally the drainsource expression as following [54-55]:

$$
\begin{aligned}
I_{D S}= & \frac{W}{L e} \frac{V_{D S} T^{2} \varepsilon_{s} \varepsilon_{0} \sigma_{0}}{2 T_{0}\left(2 T_{0}-T\right)}\left(\frac{2 T_{0} k_{B}}{\varepsilon_{s} \varepsilon_{0}}\right)^{1 / 2}\left[\frac{\left(\frac{T_{0}}{T}\right)^{4} \sin \left(\pi_{T_{0}}^{\frac{T}{-}}\right)^{\frac{T_{0}}{T}}}{(2 \alpha)^{3} B_{c}}\right]^{\frac{T_{0}}{T}-1}\left[\left(\frac{\varepsilon_{0} \varepsilon_{s}}{2 T_{a} k_{B}}\right)^{1 / 2}\left(\frac{C_{i}}{\varepsilon_{0} \varepsilon_{s}}\right)\right]^{\frac{T_{0}}{T_{0}}} \\
& {\left[\left(V_{G S}-\quad V_{t h}\right)^{\frac{2 T_{0}}{T}}-\left(V_{G S}-V_{D S}-V_{t h}\right)^{\frac{T}{T}}\right] }
\end{aligned}
$$

The final expression of drain-source current can be written as:

$$
I_{D S}=\frac{W \varphi}{L \vartheta(\vartheta-1)} \sigma_{0}\left[\frac{\left(\frac{\vartheta}{2}\right)^{4} \sin \left(\frac{2 \pi}{\vartheta}\right)}{(2 \alpha)^{3} B_{c}}\right]^{\vartheta / 2}\left[\left(V_{G S}-V_{t h}\right)^{\vartheta}-\left(V_{G S}-V_{D S}-V_{t h}\right)^{\vartheta}\right]
$$

Where, $\boldsymbol{\varphi}=\frac{V_{D S} T \varepsilon_{s} \varepsilon_{0}}{e}\left(\frac{2 T_{a} k_{B}}{\varepsilon_{s} \varepsilon_{0}}\right)^{1 / 2}\left[\left(\frac{\varepsilon_{0} \varepsilon_{s}}{2 T_{a} k_{B}}\right)^{1 / 2}\left(\frac{C_{i}}{\varepsilon_{0} \varepsilon_{s}}\right)\right]^{\frac{T_{0}}{T}-1} \quad$ and $\vartheta=\frac{2 T_{0}}{T}$

Using Eq. (11), we reproduced the transfer characteristics of $\operatorname{IF}\left(\mathrm{CN}_{2}\right)_{2}$-meta based TFTs before and after annealing treatment as represented respectively in Fig.12 (a-b).

A perfect agreement between experimental and modeled current data observed in Fig.12 (a-b) and the obtained parameters are represented in Table 1.

We note that the parameters obtained from modeling the mobility and those obtained from modeling the drain-source current in the linear regime before and after thermal annealing are close, which confirms that the charge transport in the $\operatorname{IF}\left(\mathrm{CN}_{2}\right)_{2}$-meta based TFTs can be described by VRH model. 
4.3.

deling the output characteristics

The modeling of electrical characteristics in OFETs can be performed using the same approach used for MOSFET (metal-oxide-semiconductor field effect transistor), MESFET (metal-semiconductor field effect transistor) and HFET (heterojunction field effect transistor) [56-57]. The output characteristics of $\operatorname{IF}\left(\mathrm{CN}_{2}\right)_{2}$-meta based OFETs can be modeled using the model developed by Lee et al. [58]. According to this model, the drain-source current can be expressed as [59-60]:

$$
I_{D S}=g_{c h} V_{d s e}\left(1+\lambda V_{D S}\right)+I_{0}
$$

Where, $\lambda$ is the output conductance parameter which related to physical effect, $I_{0}$ is the leakage current, $g_{c h}$ is the effective conductivity of the majority charge carriers in the conduction channel that given by [48] and $\mathrm{V}_{\text {dse }}$ is the effective source-drain voltage which given by [61]:

$$
V_{d s e}=\frac{V_{D S}}{\left[1+\left({ }^{V} D S / V_{D S s a t}\right)^{m}\right]^{m}}
$$

Where, $\mathrm{m}$ is the knee shape parameter that controls the transition between the linear and the saturation regime and $V_{\text {DSsat }}$ is the saturation voltage which can be expressed as follows:

$$
\mathrm{V}_{\mathrm{DSsat}}=\alpha_{\mathrm{s}} \times \mathrm{V}_{\mathrm{th}}\left[1+\left(\left(\mathrm{V}_{\mathrm{GS}}-\mathrm{V}_{\mathrm{th}}\right) / 2 \mathrm{~V}_{\mathrm{th}}\right)+\sqrt{\delta^{2}+\left(\left(\frac{\mathrm{V}_{\mathrm{GS}}-\mathrm{V}_{\mathrm{th}}}{\mathrm{V}_{\mathrm{th}}}\right)-1\right)^{2}}\right]
$$

Where, $\alpha_{\mathrm{s}}$ is the saturation modulation parameter and $\delta$ is the transition width parameter. Replacing Eq. (13) and Eq. (14) in Eq. (12), we obtain the expression of the drain-source current:

$$
I_{D S}=\frac{g_{c h} V_{D S}\left(1+\lambda V_{D S}\right)}{\left.\left.\left[1+\left(V_{D S} /\left(\alpha_{S} \times V_{t h}\left[1+\left(\left(V_{G S}-V_{t h}\right) / 2 V_{t h}\right)+\sqrt{\delta^{2}+\left(\left(V_{G S} V_{t h} t h\right.\right.}\right)-1\right)^{2}\right]\right)\right)^{m}\right]^{1 / m}}+I_{0}
$$

The modeling of output characteristics using Eq. (15) before and after thermal annealing is represented in Fig.13 (a-b).

As observed in Fig. 13 (a-b), the modeled output characteristics data were in a good accord with the experimental data and the obtained parameters are summarized in Table 2. 


\section{Conclusion}

In this work, we have successfully fabricated n-organic field effect transistor based on $\operatorname{IF}\left(\mathrm{CN}_{2}\right)_{2}$-meta molecule. The electrical characterization of fabricated devices shows promising results as $n$ type OFETs. A thermal annealing treatment at $150{ }^{\circ} \mathrm{C}$ for 90 min under nitrogen improves the electrical proprieties of $\operatorname{IF}\left(\mathrm{CN}_{2}\right)_{2}$-meta TFTs. To study the effect of thermal annealing on the performances of OFETs, we have characterized electrically the fabricated devices at different temperatures ranging from 300 to $380 \mathrm{~K}$. Accordingly we have estimated the activation energy of the mobility Ea and the density of states DOS of the $\operatorname{IF}\left(\mathrm{CN}_{2}\right)_{2}$-meta layer. After annealing treatment, we observed a reduction of $\mathrm{E}_{\mathrm{a}}$ which could be related to the reduction of defects number at electrodes/OSC interface accelerating thereby the charge injection into active layer. We observed also a reduction in the width of the band tail of calculated DOS which could be related to the increase ordering of $\operatorname{IF}\left(\mathrm{CN}_{2}\right)_{2}$-meta molecules after annealing treatment. In order to understand the charge transport phenomena in the $\operatorname{IF}\left(\mathrm{CN}_{2}\right)_{2}$-meta layer, we modeled the temperature dependence mobility and the current characteristics (U-V) using the VRH model. A good agreement between experimental and theoretical data was shown indicating the validity of VRH model to describe the charge conduction in the $\operatorname{IF}\left(\mathrm{CN}_{2}\right)_{2}$-meta layer.

\section{References}

[1] Y.S. Tyan, Organic Light-Emitting-Diode Lighting Overview, J. Photonics Energy 1 (2011) 011009.

[2] Q. Zheng, B. J. Jung, J. Sun, H. E. Katz, Ladder-Type Oligo-p-phenylene-Containing Copolymers with High Open-Circuit Voltages and Ambient Photovoltaic Activity, J. Am. Chem. Soc. 132 (2010) 5394-5404.

[3] C. Wang, H. Dong, W. Hu, Y. Liu, D. Zhu, Semi-Conducting P-Conjugated Systems in Field-Effect Transistors: A Material Odyssey of Organic Electronics, Chem. Rev. 112 (2012) 2208-2267.

[4] J. Mei, Y. Diao, A. L. Appleton, L. Fang, Z. Bao, Integrated Materials Design of Organic Semiconductors for Field-Effect Transistors. J. Am. Chem. Soc. 135 (2013) 6724-6746. 
[5] Y. Xu, C. Liu, D. Khim, Y.Y. Noh, Development of high-performance printed organic field-effect transistors and integrated circuits, Phys. Chem. Chem. Phys. 17 (2015) 26553-26574.

[6] JE. Anthony, A. Facchetti, M. Heeney, S.R. Marder, XW. Zhan, n-Type Organic Semiconductors in Organic Electronics, Adv. Mater. 22 (2010) 3876-3892.

[7] D.S. Chung, T.K. An, C.E. Park, H. J. Yun, S.K. Kwon, Y.H. Kim, High-speed solutionprocessed organic single crystal transistors using a novel triisopropylsilylethynyl anthracene derivative, Appl. Phys. Lett. 101 (2012) 193304.

[8] T.W. Kelley, P.F. Baude, C. Gerlanch, D.E. Ender, D. Muyres, M.A. Haase, D.E. Voge, S.D. Theiss, Recent Progress in Organic Electronics: Materials, Devices, and Processes Chem. Mater. 16 (2004) 4413-4422.

[9] V. Podzorov, S.E. Sysoev, E. Loginova, V.M. Pudalov, M.E. Gershenson, Single-Crystal Organic Field Effect Transistors with the hole mobility $\sim 8 \mathrm{~cm} 2 / \mathrm{Vs}$, Appl. Phys. Lett. 83 (2003) 3504.

[10] I. Mcculloch, M. Heeney, C. Bailey, C. Genevicius, I. Macdonald, M. Shkunov, et al., Liquid-crystalline semiconducting polymers with high charge-carrier mobility, Nat. Mater. 5 (2006) 328-333.

[11] R. Fang, R. Chen, J. Gao, H. Zhang, H. Wu, H. Li, Chalcogen bridged pyrene derivatives: Synthesis, crystal-packing structures and field effect transistors properties, Org. Electron. 45 (2017) 108-114.

[12] T. Okamoto, Z. Bao, Synthesis of Solution-Soluble Pentacene-Containing Conjugated Copolymers, J. Am. Chem. Soc. 129 (2007) 10308-10309.

[13] Q. Meng, W. Hu, Recent progress of n-type organic semiconducting small molecules for organic field-effect transistors, Phys. Chem. Chem. Phys. 14 (2012) 14152 -14164.

[14] M. Petit, R. Hayakawa, T. Chikyow, J.P. Hill, K. Ariga, Y. Wakayama, Variable temperature characterization of $\mathrm{N}, \mathrm{N}^{\prime}$-Bis(n-pentyl)terrylene-3,4:11,12-tetracarboxylic diimide thin film transistor, Org. Electron. 10 (2009) 1187-1190.

[15] J. Puigdollers, C. Voz, S. Cheylan, A. Orpella, M. Vetter, R. Alcubilla, Fullerene thinfilm transistors fabricated on polymeric gate dielectric, Thin Solid Films 515 (2007) $7667-7670$.

[16] J.D. Peltier, B. Heinrich, B. Donnio, J. Rault-Berthelot, E. Jacques, et al., ElectronDeficient Dihydroindaceno-Dithiophene Regioisomers for n-Type Organic Field-Effect Transistors, ACS Appl. Mater. Interfaces 9 (2017) 8219-8232. 
[17] C. Poriel, F. Barrière, D. Thirion, J. Rault-Berthelot, Encumbered DiSpiro[FluoreneIndenoFluorene]: Mechanistic Insights, Chem. Eur. J. 15 (2009) 13304-13307.

[18] D. Thirion, C. Poriel, R. Métivier, J.; Barrière, F. Rault-Berthelot, O. Jeannin, Violetto-Blue Tunable Emission of Aryl-Substituted Dispirofluorene-Indenofluorene Isomers by Conformationally-Controllable Intramolecular Excimer Formation, Chem. Eur. J. 17 (2011) 10272-10287.

[19] C. Poriel, J. Rault-Berthelot, D. Thirion, F. Barrière, L. Vignau, Blue Emitting $3 \pi-$ 2 Spiro Terfluorene-Indenofluorene Isomers: A Structure-Properties Relationship Study, Chem. Eur. J. 17 (2011) 14031-14046.

[20] M. Romain, C. Quinton, D. Tondelier, B. Geffroy, O. Jeannin, J. Rault- Berthelot, C. Poriel, Thioxanthene and dioxothioxanthene dihydroindeno[2,1-b]fluorenes: synthesis, properties and applications in green and sky blue phosphorescent OLEDs, J. Mater. Chem. C 4 (2016) 1692-1703.

[21] M. Romain, D. Tondelier, B. Geffroy, O. Jeannin, E. Jacques, J. Rault-Berthelot, and C. Poriel, Donor/Acceptor Dihydroindeno[1,2-a]fluorene and Dihydroindeno[2,1b]fluorene: Towards New Families of Organic Semiconductors, Chem. Eur. J. 21 (2015) $9426-9439$.

[22] C. Poriel, R. Métivier, J. Rault-Berthelot, D. Thirion, F. Barrière, O. Jeannin, A robust pure hydrocarbon derivative based on the (2,1-b)-indenofluorenyl core with high triplet energy level. Chem. Commun. 47 (2011) 11703-11705.

[23] Q. Zheng, B. J. Jung, J. Sun, H. E. Katz, Ladder-Type Oligo-p-phenylene-Containing Copolymers with High Open-Circuit Voltages and Ambient Photovoltaic Activity, J. Am. Chem. Soc. 132 (2010) 5394-5404.

[24] M. Romain, M. Chevrier, S. Bebiche, T. Mohammed-Brahim, J. Rault- Berthelot, E. Jacques, C. Poriel, The structure-property relationship study of electron-deficient dihydroindeno[2,1-b]fluorene derivatives for n-type organic field effect transistors, J. Mater. Chem. C 3 (2015) 5742-5753.

[25] S. Bebiche, P. Cisneros-Perez, T. Mohammed-Brahim, M. Harnois, J. Rault - Berthelot, C. Poriel, E. Jacques, Influence of the gate bias stress on the stability of n-type Organic Field-Effect Transistors based on Dicyanovinylenes-Dihydroindenofluorene semiconductors. Materials Chemistry Frontiers 2018, 10.1039/C8QM00193F.

[26] S. Bebiche, I. Bouhadda, T. Mohammed-Brahim, N. Coulon, J.F. Bergamini, C. Poriel, E. Jacques, Performance improvement of IF(CN2)2 meta based N-channel OTFTs and their integration into a stable CMOS inverter, Solid-State Electronics 130 (2017) 49-56. 
[27] R.P. Ortiz, H. Herrera, C. Seoane, J.L. Segura, A. Facchetti, T.J. Marks, Rational design of ambipolar organic semiconductors: is core planarity central to ambipolarity in thiophene-naphthalene semiconductors?, Chemistry - A European Journal 18 (2012) $532-543$.

[28] P.R Ortiz , H. Herrera, R. Blanco, H. Huang, A. Facchetti, T.J. Marks, et al., Organic nchannel field-effect transistors based on arylenediimide-thiophene derivatives, J. Am. Chem. Soc. 132 (2010) 8440-8452.

[29] M. Mas-Torrent, P. Hadley, S.T. Bromley, X. Ribas, J. Tarrés, M. Mas, et al., Correlation between crystal structure and mobility in organic field-effect transistors based on single crystals of tetrathiafulvalene derivatives, J. Am. Chem. Soc. 126 (2004) 8546-8553.

[30] S.J. Kang, S. Song, C. Liu , D.Y. Kim , Y.Y. Noh, S.J. Kang et al., Evolution in crystal structure and electrical performance of thiophene-based polymer field effect transistors: A remarkable difference between thermal and solvent vapor annealing, Org. Electron. 15 (2014) 1972-1982.

[31] T.B. Singh, P. Senkarabacak, N.S. Sariciftci, A. Tanda, C. Lackner, R. Hagelauer, G. Horowitz, Organic inverter circuits employing ambipolar pentacene field-effect transistors, Appl. Phys. Lett. 89 (2006) 033512.

[32] M.J. An, H.S. Seo, Y. Zhang, J.D. Oh, J.H. Choi, Air stable, ambipolar organic transistors and inverters based upon a heterojunction structure of pentacene on $\mathrm{N}, \mathrm{N}^{\prime}$ ditridecylperylene-3,4,9,10-tetracarboxylic di-imide, Appl. Phys. Lett. 97 (2010) 023506.

[33] S. Zorai and R. Bourguiga, Analytical model for charge transport in organic thin-film transistors: application to polythiophène, Eur. Phys. J. Appl. Phys. 59 (2012) 20201.

[34] M.E. Gershenson, V. Podzorov, A.F. Morpurgo, Electronic transport in single-crystal organic transistors, Rev. Mod. Phys. 78 (2006) 973.

[35] T.J. Ha, P.Sonar, B. Cobb, A. Dodabalapur, Charge transport and density of trap states in balanced high mobility ambipolar organic thin-film transistors, Org. Electron. 13 (2012) $136-141$.

[36] X. Li, A. Kadashchuk, I.I. Fishchuk, W.T.T. Smaal, G. Gelinck, Dirk J. Broer, J. Genoe, P. Heremans, H. Bässler, Electric Field Confinement Effect on Charge Transport in Organic Field-Effect Transistors, Phys. Rev. Lett. 108 (2012) 066601.

[37] G. Horowitz, P. Delannoy, An analytical model for organic-based thin-film transistors, J. Appl. Phys. 70 (1991) 469. 
[38] P.V. Necliudov, M.S. Shur, D.J. Gundlach, T.N. Jackson, Modeling of organic thin film transistors of different designs, J. Appl. Phys. 88 (2000) 6594

[39] M. Matters et al., Organic field-effect transistors and all-polymer integrated circuits, Opt. Mater. 12 (1999) 189-197.

[40] G. Horowitz, R. Hajlaoui, P. Delannoy, Temperature Dependence of the Field-Effect Mobility of Sexithiophene. Determination of the Density of Traps, J. Phys. III France 5 (1995) 355-371.

[41] M. C. J. M. Vissenberg and M. Matters, Theory of the field-effect mobility in amorphous organic transistors, Phys. Rev. B 57 (1998) 12964.

[42] R. S. Muller and T. I. Kamins, Device Electronics for Integrated Circuits, 3rd Ed, Wiley, New York, (1986).

[43] J.A. Letizia, J. Rivnay, A. Facchetti, M.A. Ratner, T.J. Marks, Variable Temperature Mobility Analysis of n-Channel, p-Channel, and Ambipolar Organic Field-Effect Transistors, Adv. Funct. Mater. 20 (2010) 50-58.

[44] K.P. Pernstich, S. Haas, D. Oberhoff, C. Goldmann, D.J. Gundlach, B. Batlogg, A.N. Rashid, G. Schitter, Threshold voltage shift in organic field effect transistors by dipole monolayers on the gate insulator, J. Appl. Phys. 96 (2004) 6431.

[45] D.V. Lang, X. Chi, T. Siegrist, A.M. Sergent, A.P. Ramirez, Amorphous-like Density of Gap States in Single-Crystal Pentacene, Phys. Rev. Lett. 93 (8) (2004) 086802.

[46] A.R. Völkel, R.A. Street, D. Knipp, Carrier transport and density of state distributions in pentacene transistors, Phys. Rev. B 66 (2002) 195336.

[47] C. Voz, A. Marsal, C. Moreno, J. Puigdollers, R. Alcubilla, Comparison between the density-of-states of picene transistors measured in air and under vacuum, Synth. Met. 161 (2012) 2554-2557

[48] S. Mansouri, G. Horowitz, R. Bourguiga, Modeling of mobility in organic thin-film transistor based octithiophene (8T), Synth. Met. 160 (2010) 1787-1792.

[49] M. Sahimi, Applications of Percolation Theory, $1^{\text {st }}$ Ed., Taylor \& Francis, London, 1994. 
[50] G.E. Pike, C.H. Seager, Percolation and conductivity: A computer study, Phys. Rev. B 10 (1974)1421.

[51] L. Torsi, A. Dodabalapur, H.E. Katz, An analytical model for short-channel organic thin-film transistors, J. Appl. Phys. 78 (1995) 1088.

[52] L. Li, H. Kosina, An analytical model for organic thin film transistors, Conference on Electron Devices and Solid- State Circuits, Hong Kong, IEEE, 2005, pp. 571-574.

[53] E. Calvetti, L. Colalongo, Zs.M. Kovács-Vajna, Organic thin film transistors: a DC/dynamic analytical model, Solid-State Electron. 49 (2005) 567-577.

[54]S. Zorai, S. Mansouri, R. Bourguiga, The effects of the nature of dielectric layers on the electric properties of organic thin-film transistor based on octithiophene (8T), Superlattices and Microstructures 55 (2013) 211-221

[55] A. Jouili, S. Mansouri, Ahmed Al-Ghamdi, L. El Mir, F. Yakuphanoglu, Controlling of DOS of TFTs based 6,13-bis(triisopropylsilylethynyl) pentacene by solar light illumination, Synth. Met. 220 (2016) 591-598.

[56] M.S. SHUR et al, Unified GaAs MESFET model for circuit simulations, Int. J. Hi. Spe. Ele. Syst. 03 (1992) 201.

[57] M. Shur, T. A. Fjeldly, T. Ytterdal and K. Lee, Unified MOSFET model, Solid-State Electronics 35 (1992) 1795-1802.

[58] K. Lee, M. Shur, T. Fjeldly, T. Ytterdal, Semiconductor Device Modeling for VLSI, $1^{\text {st }}$ Ed., Prentice-Hall, New Jersey USA, 1993.

[59] W. Boukhili, M. Mahdouani, M. Erouel, J. Puigdollers, R. Bourguiga, Reversibility of humidity effects in pentacene based organic thin-film transistor: Experimental data and electrical modeling, Synth. Met. 199 (2015) 303-309.

[60] S. Mansouri, S. Zorai, R. Bourguiga, The overall device resistance in organic thin film transistor: Application to octithiophene (8T), Synth. Met. 162 (2012) 231- 235.

[61] M. Bartzsch, H. Kempa, M. Otto, A. Hübler, D. Zielke, Device and circuit simulation of printed polymer electronics, Org. Electron. 8 (2007) 431-438. 


\section{Figure captions:}

Figure 1: A schematic view of bottom-gate bottom-contact $\operatorname{IF}\left(\mathrm{CN}_{2}\right)_{2}$-meta based TFTs.

Figure 2: (a) Chemical molecular structure of $\left(\operatorname{IF}\left(\mathrm{CN}_{2}\right)_{2}\right.$-meta) and (b) the Atomic Force Microscopy (AFM) image of $\operatorname{IF}\left(\mathrm{CN}_{2}\right)_{2}$-meta film deposed at substrate temperature of $80^{\circ} \mathrm{C}$.

Figure 3 (a): Output characteristic curves ( $\mathrm{I}_{\mathrm{DS}}$ versus $\left.\mathrm{V}_{\mathrm{DS}}\right)$ and (b) transfer characteristics curves ( $\mathrm{I}_{\mathrm{DS}}$ versus $\mathrm{V}_{\mathrm{GS}}$ at $\mathrm{V}_{\mathrm{DS}}=10 \mathrm{~V}$ of $\operatorname{IF}\left(\mathrm{CN}_{2}\right)_{2}$-meta based -TFTs.

Figure 4: (a) Output characteristics measured before thermal annealing, (b) Output characteristics measured after thermal annealing.

Figure 5: (a) Comparison between transfer characteristics extracted at $\mathrm{V}_{\mathrm{DS}}=10 \mathrm{~V}$ before and after thermal annealing, (b) comparison between extracted linear mobility before and after annealing treatment.

Figure 6: transfer characteristics measured at different temperatures varied from $300 \mathrm{~K}$ to $380 \mathrm{~K}$ (a) before annealing treatment, (b) after annealing treatment

Figure 7 (a): Variation of threshold voltages $V_{\text {th }}$ versus temperature $T$ extracted before and after annealing treatment (b) Variation of density of states $\mathrm{N}_{\text {tr }}$ versus temperature $\mathrm{T}$ the extracted before and after annealing treatment.

Figure 8: Variation of mobility $\mu_{\mathrm{FET}}$ versus gate voltage $\mathrm{V}_{\mathrm{GS}}$ at various temperatures extracted (a) before thermal annealing (b) after thermal annealing.

Figure 9: Arrhenius plot of the temperature dependence mobility for different gate voltage extracted (a) before annealing treatment, (b) after annealing treatment. 
Figure 10: (a) Variation of the activation energy of the mobility $E_{a}$ versus the gate voltage $\mathrm{V}_{\mathrm{GS}}$ compared before and after annealing treatment, (b) Variation of the density of states DOS versus the activation energy $E_{a}$ compared before and after thermal annealing.

Figure 11: The good agreement between experimental (circle line) and that obtained from Eq. (8) (full line) temperature dependence mobility of $\operatorname{IF}\left(\mathrm{CN}_{2}\right)_{2}$-meta based TFTs: (a) before thermal annealing and (b) after thermal annealing.

Figure 12: The good agreement between experimental (circle line) and that obtained from Eq. (11) (full line) transfer characteristics of $\operatorname{IF}\left(\mathrm{CN}_{2}\right)_{2}$-meta based TFTs at different temperature: (a) before thermal annealing and (b) after thermal annealing.

Figure 13 (a-b): The good agreement between experimental (circle line) and that obtained from Eq. (15) (full line) output characteristics of $\operatorname{IF}\left(\mathrm{CN}_{2}\right)_{2}$-meta based TFTs : (a) before thermal annealing and (b) after thermal annealing.

\section{Table's caption}

Table 1: Comparison between parameter values that give a good agreement between the measured and theoretical mobility and parameter values that give a good agreement between the measured and theoretical transfer characteristics.

Table 2: Parameter values that give a good agreement between the measured output characteristics and those obtained by Eq. (15). 


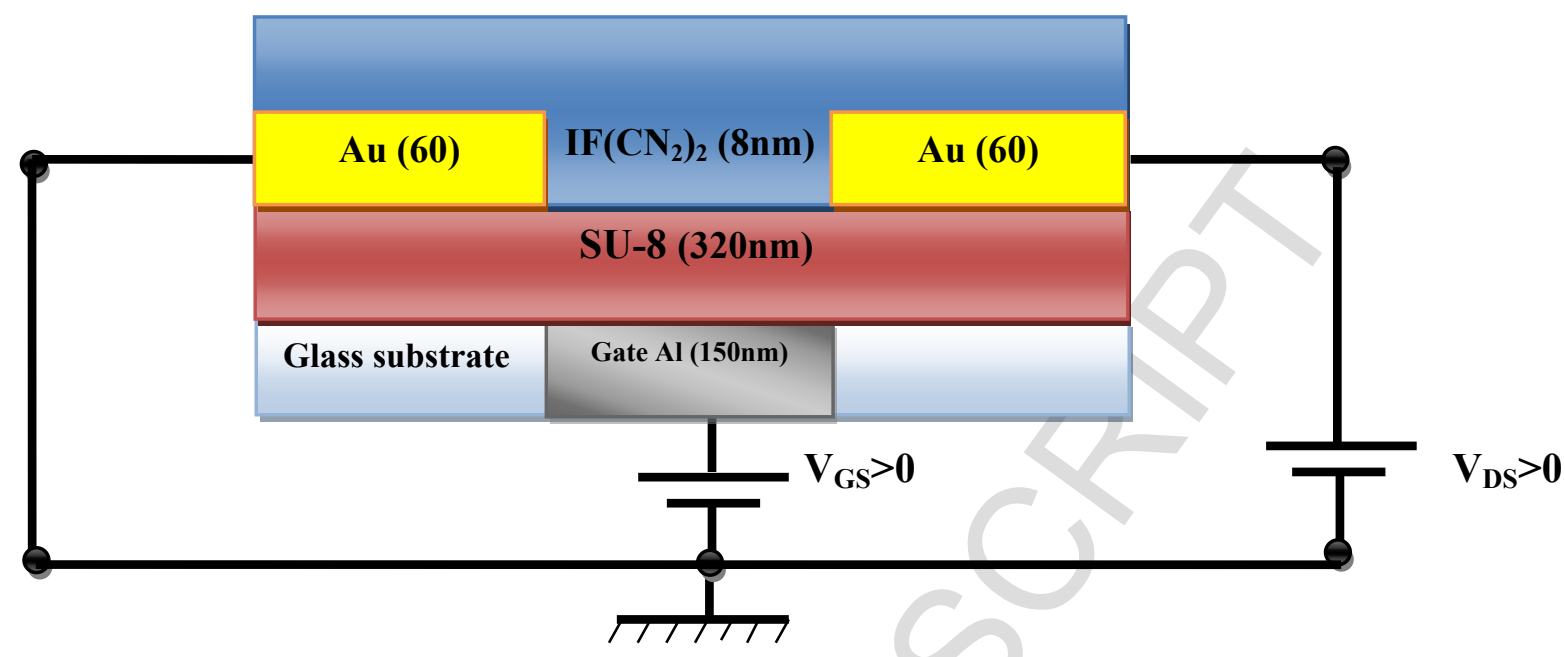

Figure 1

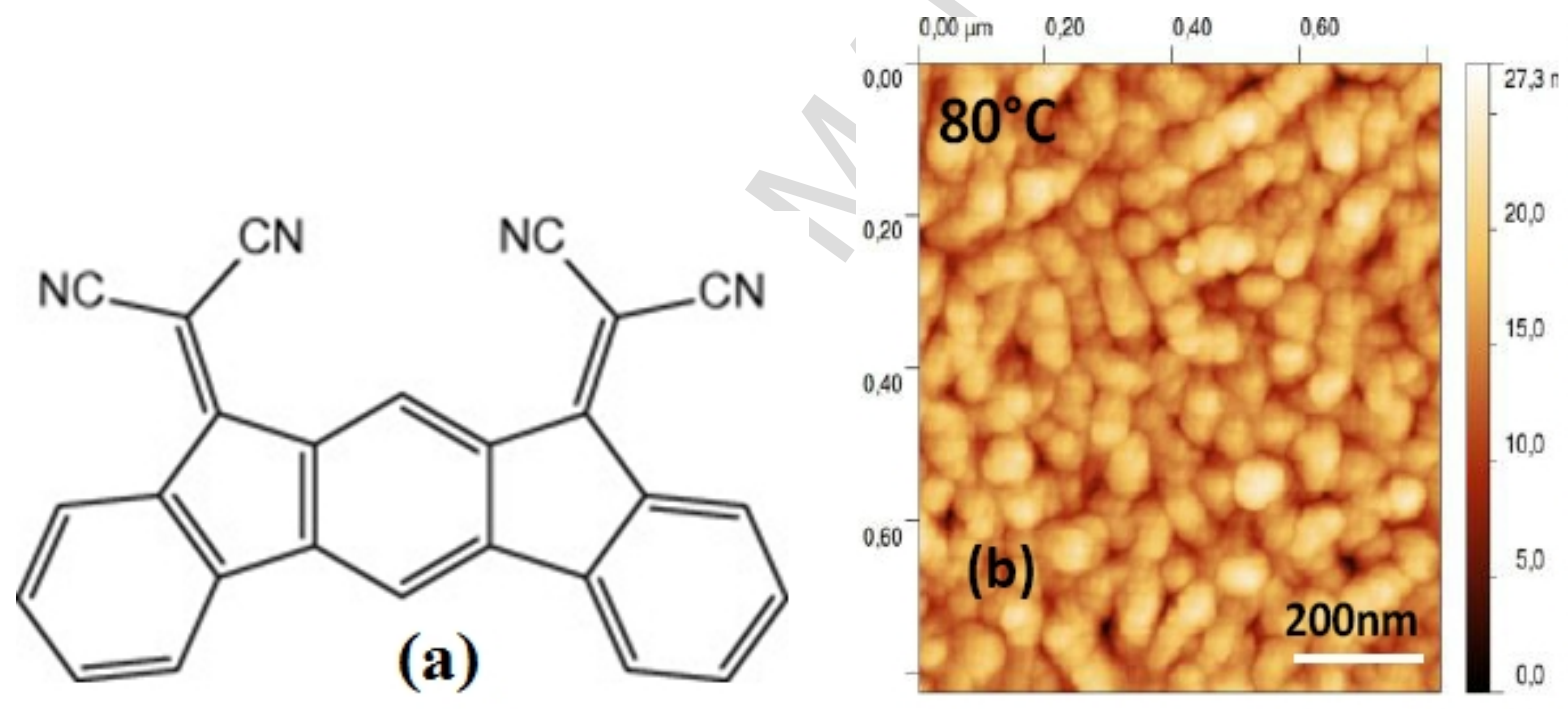

Figure 2 

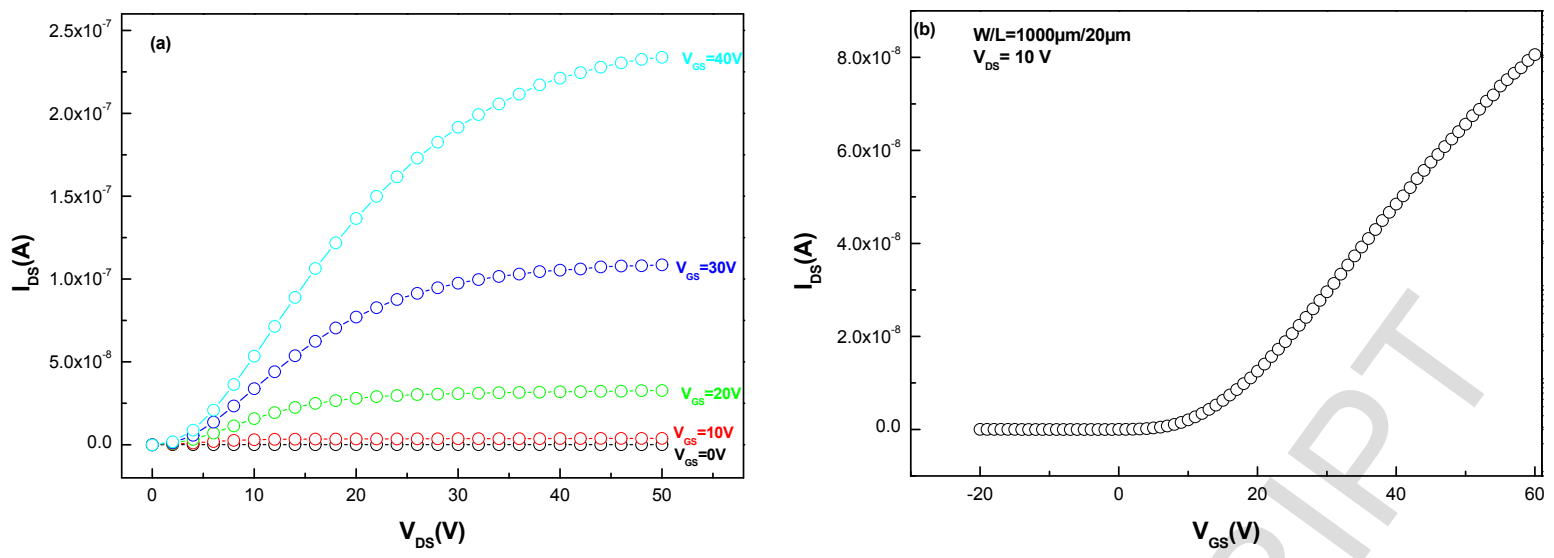

Figure 3
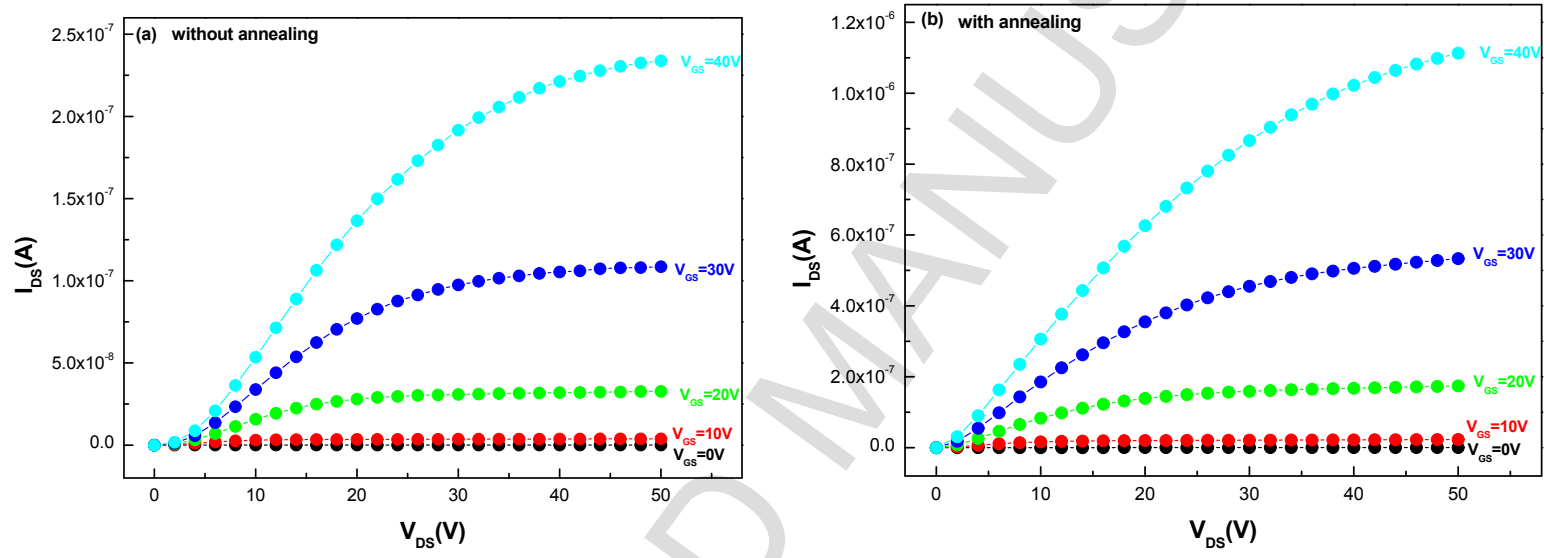

Figure 4
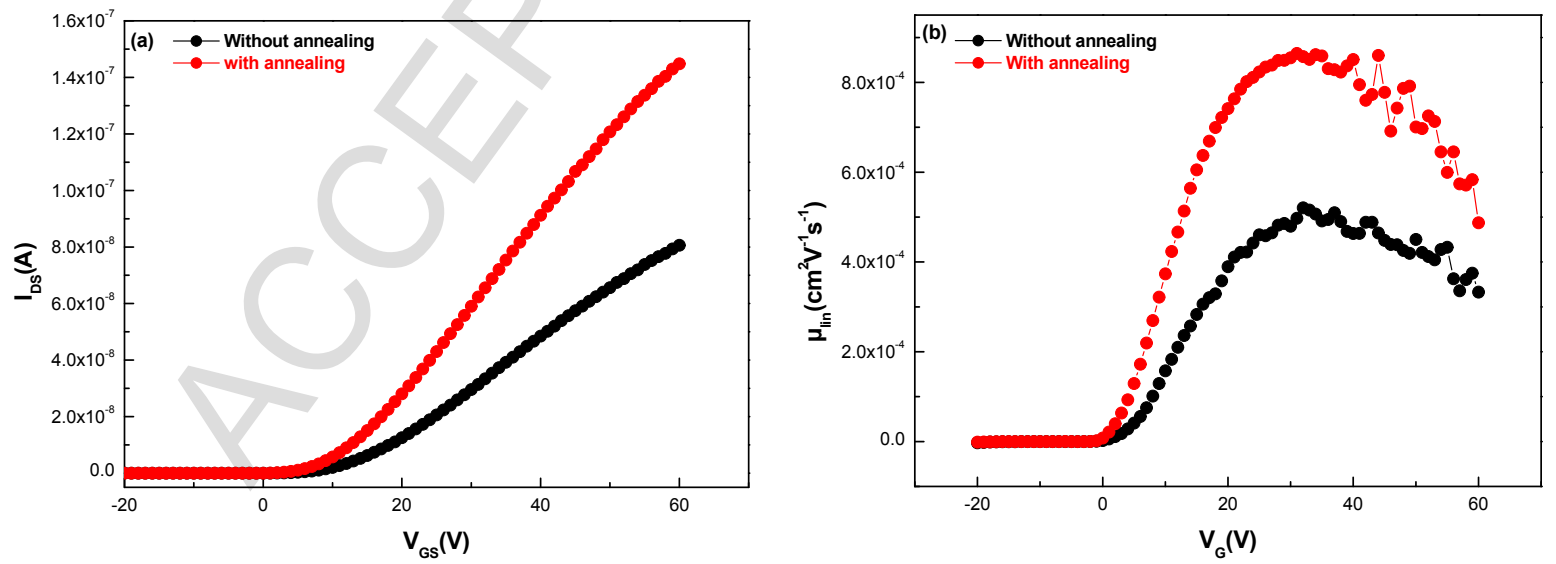

Figure 5 

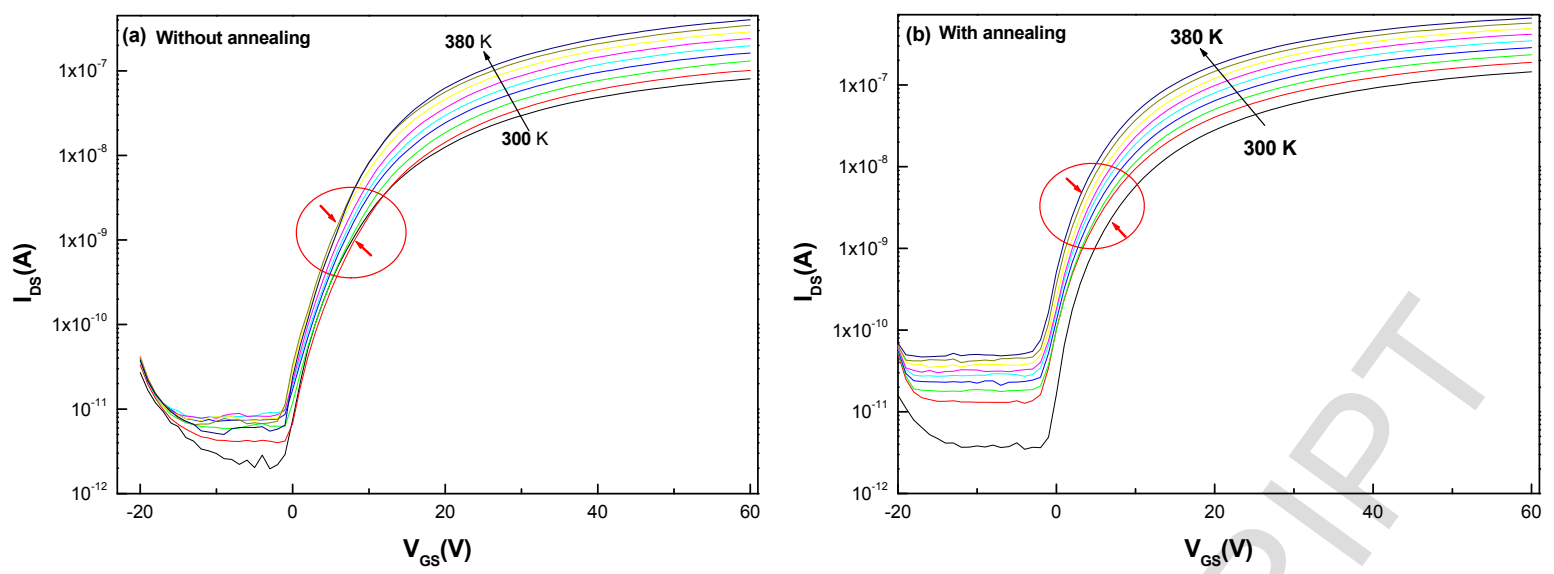

Figure 6
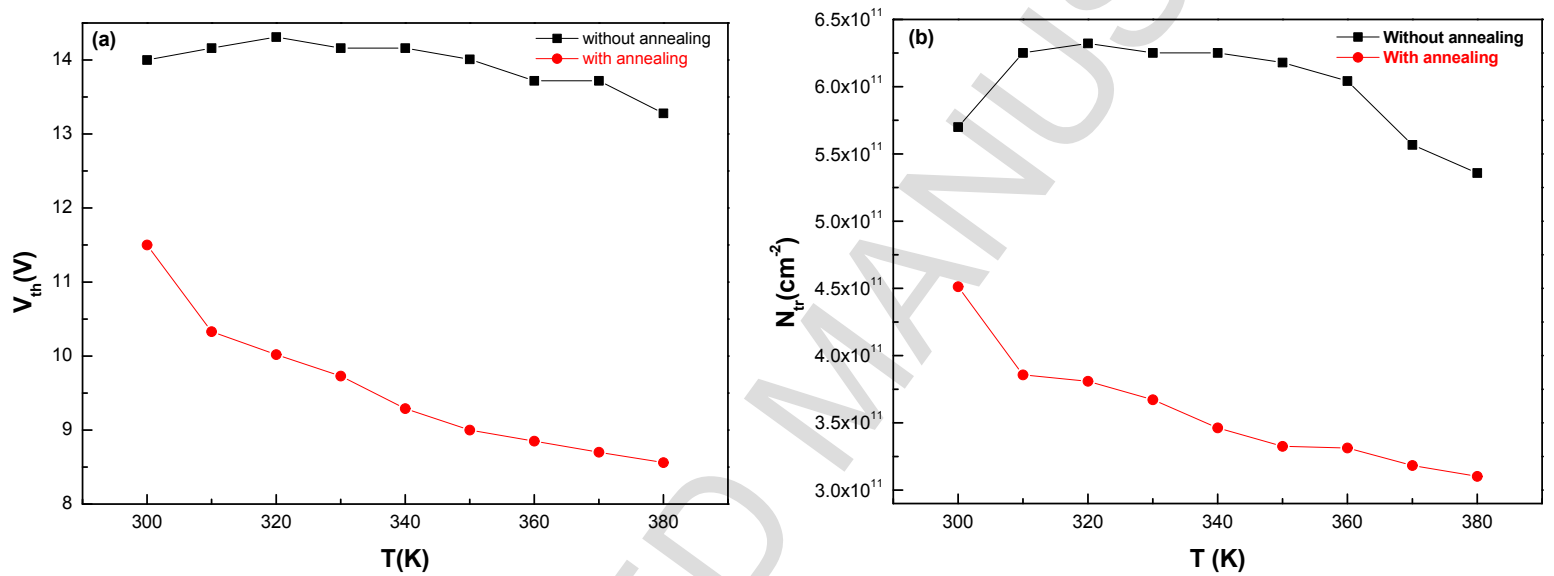

Figure 7 

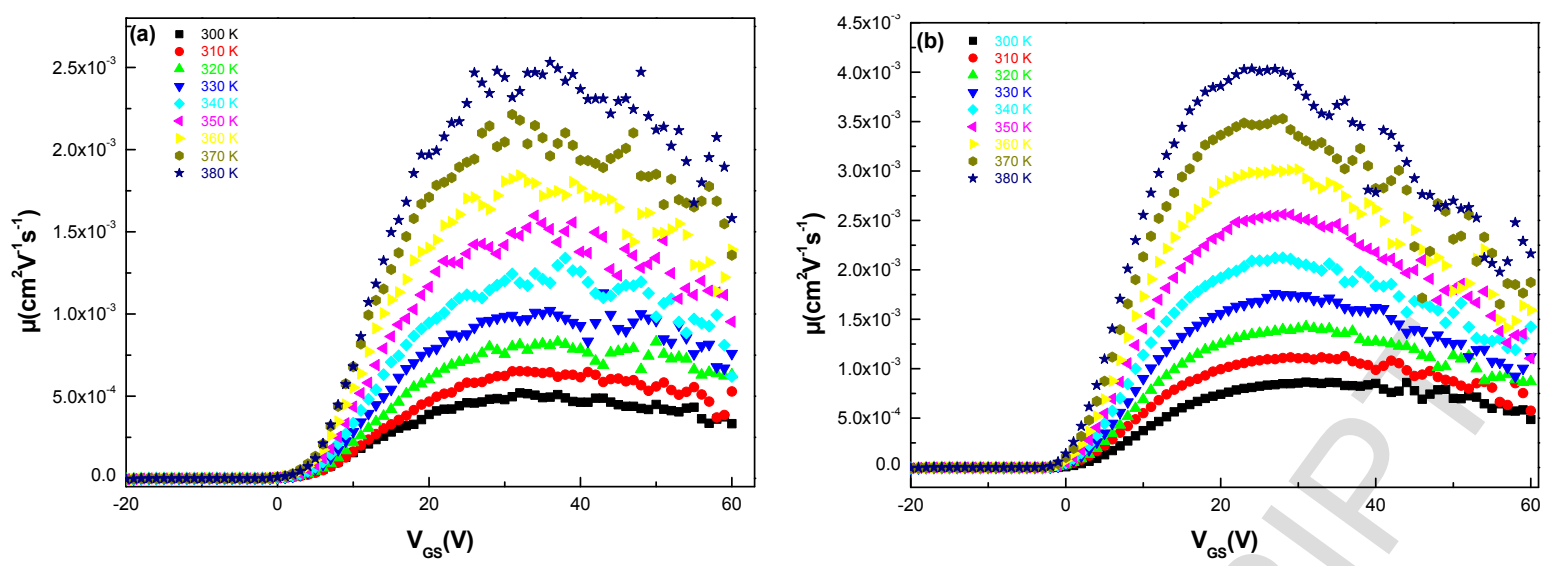

Figure 8
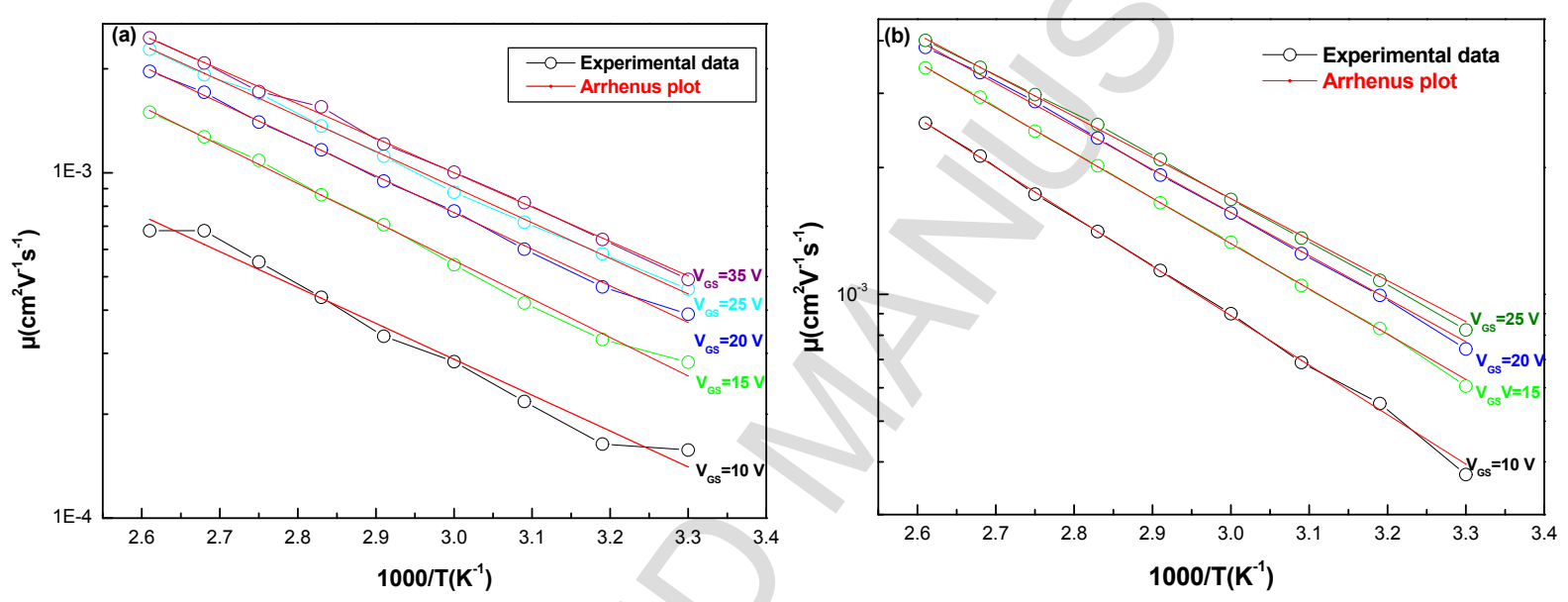

Figure 9
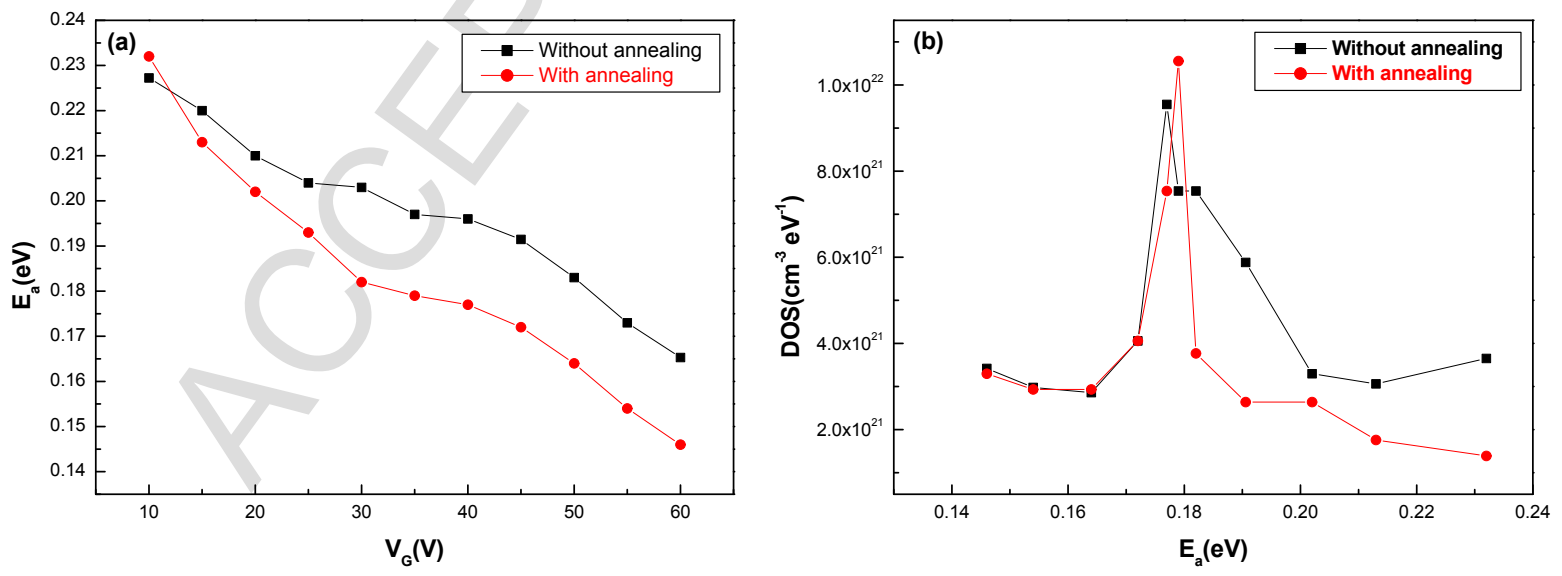

Figure 10 

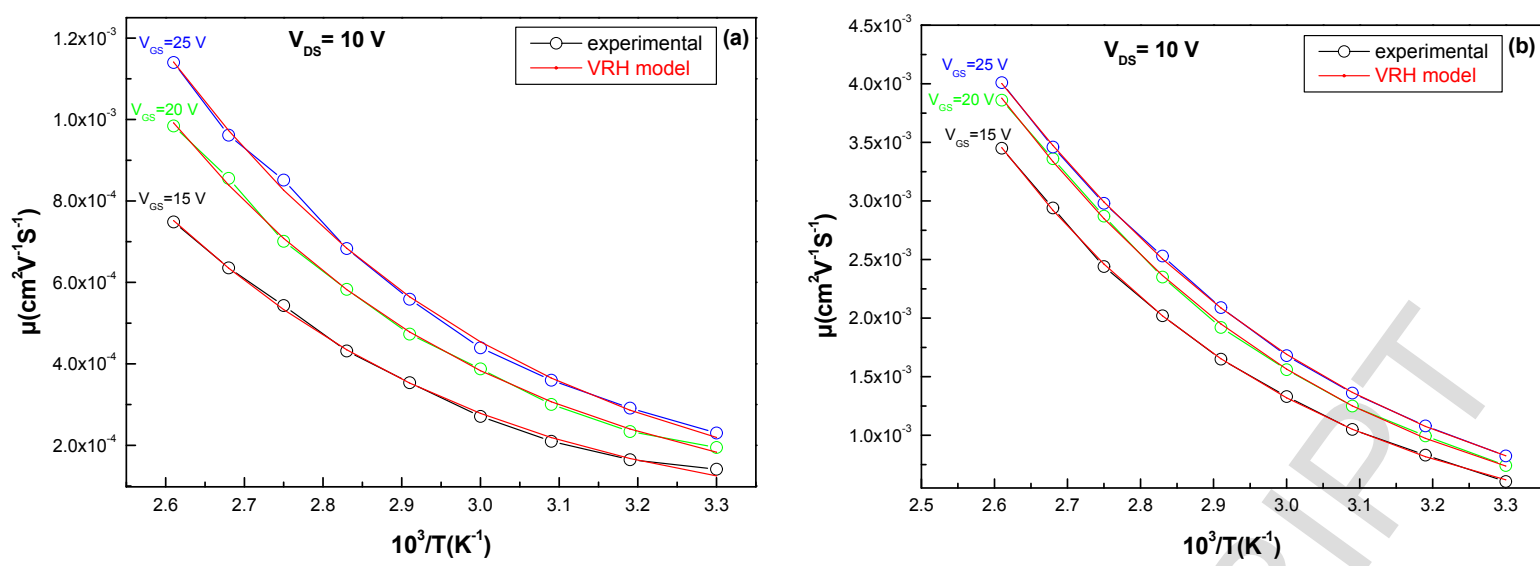

Figure11
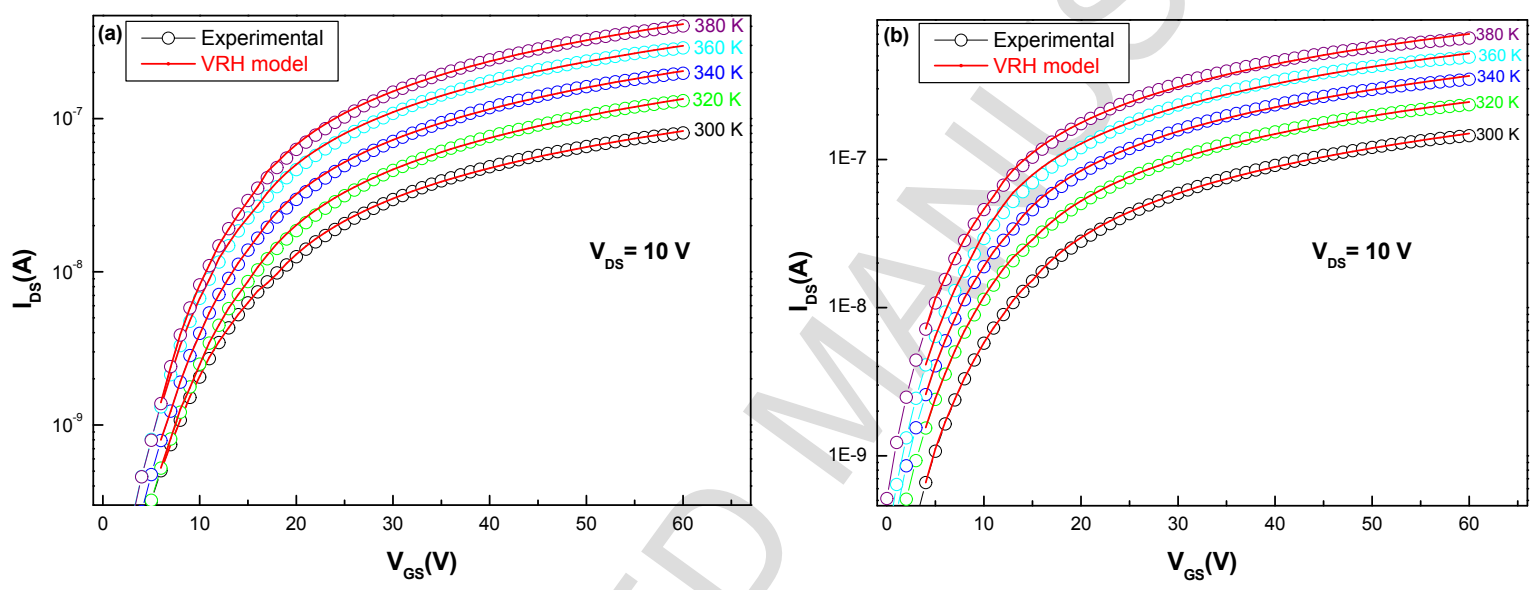

Figure 12
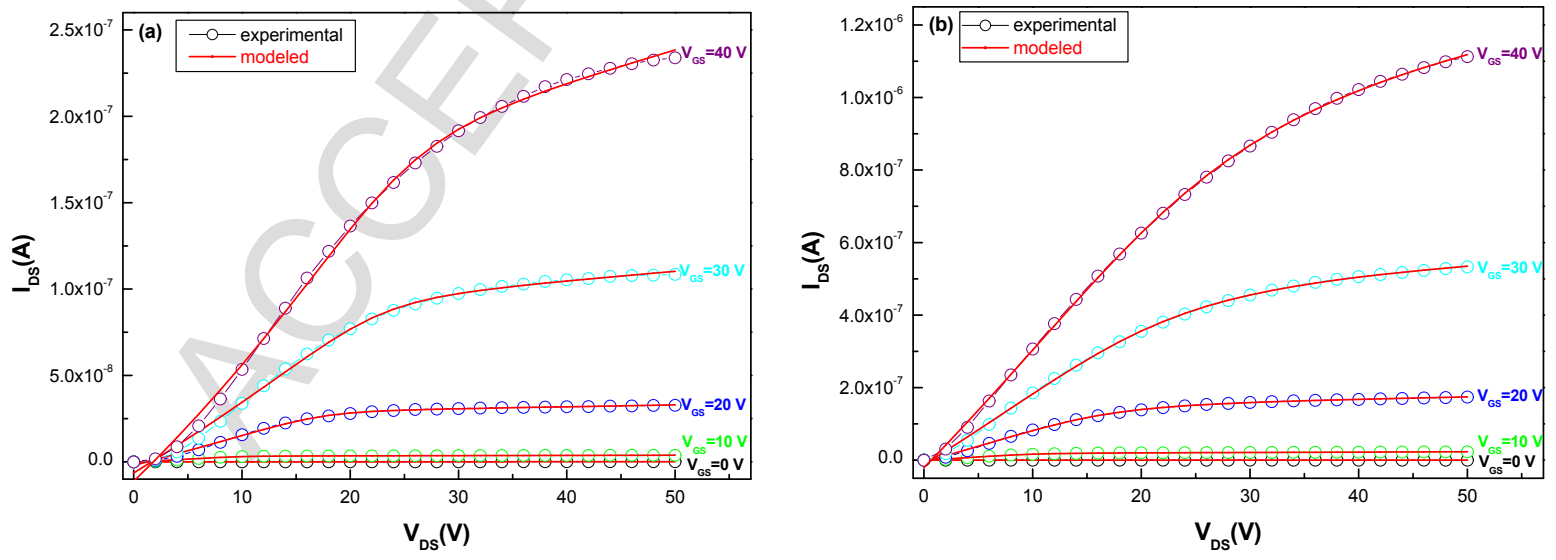

Figure 13 


\section{Highlights}

- Bottom gate-bottom contact $\operatorname{IF}\left(\mathrm{CN}_{2}\right)_{2}$-meta based TFTs were successfully fabricated, using the epoxy based photoresist SU-8 as organic gate insulator.

- The performances of fabricated devices were enhanced by a thermal annealing at 150 ${ }^{\circ} \mathrm{C}$ under nitrogen.

- The thermal behavior of $\operatorname{IF}\left(\mathrm{CN}_{2}\right)_{2}$-meta based TFTs was analyzed.

- The annealing effect on the activation energy of mobility $\mathrm{E}_{\mathrm{a}}$ and the density of states DOS was investigated.

- An analytical model based on variable range hopping (VRH) theory was reported to model the fabricated OFETs and to understand the charge transport mechanism dominating in the $\operatorname{IF}\left(\mathrm{CN}_{2}\right)_{2}$ meta molecule.

- Using this model, the dependence of mobility with temperature, the transfer and output characteristics were successfully reproduced. 
Table 1

\begin{tabular}{|l|c|c|c|c|c|c|}
\hline \multirow{2}{*}{} & \multicolumn{2}{|c|}{$\mathrm{T}_{\mathrm{a}}(\mathrm{K})$} & \multicolumn{2}{c|}{$\sigma_{0}\left(\mathrm{Sm}^{-1}\right)$} & \multicolumn{2}{c|}{$\alpha^{-1}(\AA)$} \\
\cline { 2 - 7 } & Fit $\mu_{\mathrm{FET}}$ & Fit $\mathrm{I}_{\mathrm{DS}}$ & Fit $\mu_{\mathrm{FET}}$ & Fit $\mathrm{I}_{\mathrm{DS}}$ & Fit $\mu_{\mathrm{FET}}$ & Fit $\mathrm{I}_{\mathrm{DS}}$ \\
\hline Without annealing & 318 & 320 & $9.65 \times 10^{10}$ & $1.03 \times 10^{11}$ & 0.29 & 0.31 \\
\hline With annealing & 310 & 311 & $10.13 \times 10^{11}$ & $9.89 \times 10^{11}$ & 0.086 & 0.091 \\
\hline
\end{tabular}

Table 2

\begin{tabular}{|c|c|c|c|c|c|}
\hline & $\lambda\left(\mathrm{V}^{-1}\right)$ & $\mathrm{m}$ & $\mathrm{V}_{\mathrm{DSsat}}(\mathrm{V})$ & $\mathrm{R}_{\mathrm{ch}}(\Omega)$ & $\mathrm{I}_{0}(\mathrm{~A})$ \\
\hline Without annealing & 0.0091 & 6.1 & 15.44 & $9.07 \times 10^{8}$ & $8.96 \times 10^{-9}$ \\
\hline With annealing & 0.0195 & 5.33 & 16.75 & $1.85 \times 10^{8}$ & $7.96 \times 10^{-9}$ \\
\hline
\end{tabular}

